\title{
Stress field characterisation in Nickel Rim South Mine using seismic stress inversion
}

\author{
Y Abolfazlzadeh Queen's University, Canada \\ SD McKinnon Queen's University, Canada
}

\begin{abstract}
Knowledge of stresses is important for many aspects of mine design, but conventional methods of measuring stresses produce estimates at only a limited number of points in space and time. Furthermore, stresses are known to be affected by geological structures, particularly faults, but mapping of how the stress field is affected by such structures is not currently possible. Therefore, there is a compelling reason to consider the use of techniques that can map such local stress field variations. The method of seismic stress inversion is utilised to address this limitation and its application is illustrated using seismic data collected from Nickel Rim South Mine (NRS) located in Sudbury, Ontario, Canada. NRS is a modern mine using blasthole open stoping with backfill as a means of bulk mining. The ellipsoidally shaped orebody is located between 1,160 and $1,710 \mathrm{~m}$ below ground surface, strikes east-west and is steeply dipping. Although the NRS host rock and orebody are relatively massive with high strength, the mine is structurally complicated. Many faults appear to influence the stress field, in addition to being the sources of seismic events. The seismic monitoring array in NRS has good coverage over the active volume of the mine and consists of uniaxial and triaxial geophones and accelerometers. This combination of sensors results in a large catalogue of events with good focal sphere coverage that permits source mechanism analyses to be performed. Extensive filtering has been applied to the seismic data to improve the quality, and for the stress inversion process the first motion stress inversion (MOTSI) software is used. MOTSI only uses the first motion polarities and estimates the stress tensor components with more complete uncertainties compared to other nonlinear methods. To facilitate development and refinement of the seismic stress inversion process, numerous clusters of seismic events over a period of seven months during the early stages of mining were initially analysed so as to minimise perturbations caused by the interaction between mining and geological structures. More than 500 manually processed events throughout the mine are utilised for the stress inversions. Results show that the clusters in the earlier stages of mining and further away from excavation boundaries demonstrate reasonable agreement with pre-mining stress estimates based on overcoring and breakouts.
\end{abstract}

Keywords: microseismic monitoring, seismicity, stress mapping, seismic stress inversion

\section{Introduction}

The Factor of Safety commonly used in rock mass stability analysis is generally defined as the ratio between the strength and stress. Compared to the rock mass strength, which can be estimated reasonably well from rock mass classification, the in situ stress conditions are not as well known.

Stress measurement techniques have had few progresses since the development of the hollow inclusion cell in the late 1970's (Worotnicki \& Walton 1976). Also, the simplified linear stress field format is not consistent with evidence from earth science research results, though it is generally used in practice. It has also been found that geological structures, such as faults and dykes, can have a significant effect on both the magnitude and orientation of stresses (Michael 1987; McKinnon \& Garrido 1998; Gudmundsson \& Homberg 1999; McKinnon 2006; McKinnon \& Labrie 2006; Baird et al. 2009, 2010).

Generally, in situ stress measurement methods can be classified into two main types, methods that disturb the in situ rock conditions and methods without any major influence from the measuring methods (Ljunggren et al. 2003). The former stress measurement methods have many limitations such as reliance on the borehole 
orientation, quantifying stress at a small number of points in the rock mass, difficulty in interpretation, and cost (Ljunggren et al. 2003). The latter methods (fault plane solution and moment tensor inversion) are based on slip directions of seismic events resulting from shear failure and were developed for use in crustal seismology for resolution of earthquake mechanics, very large faults, palaeostress, and very large scale stress assessments (Angelier 1990, 1994; Etchecopar et al. 1981; Michael 1984; Delvaux \& Sperner 2003). Most of the stress inversion techniques are based on the two assumptions proposed by Wallace (1951) and Bott (1959):

- Slip vector is parallel to the resolved shear stress on the fault surface.

- The stress is uniform in the volume under consideration.

Seismic stress inversion produces four out of the six parameters of the stress tensor, which includes three orientations of principal stresses plus the ratio between the magnitudes of principal stresses $\left(R=\frac{\sigma 2-\sigma 1}{\sigma 3-\sigma 1}\right)$, i.e. it does not produce the absolute magnitudes of principal stresses, only the relative magnitudes between them.

This method has the potential to provide a detailed view of the three-dimensional (3D) nature of the stress field by sampling the stress field at many locations within the seismogenic zones near mining excavations and active faults. Focal mechanism (known as fault plane solution in the case of fault slip related events) and seismic moment tensor inversion are the most frequently used techniques for seismic stress inversion. The focal mechanism is based on the first motion of the P-wave arrival. When fault slip or rock mass failure occurs, the resulting seismic event has some characteristics (i.e. arrival time, initial polarities, and location) that can be assessed in order to determine the local state of stress. For a shear slip motion on a fault surface, seismic waves radiating from the hypocentre in all directions are plotted in a lower-hemisphere stereographic projection (Figure 1). According to the polarity of the P-wave arrivals, the area around the hypocentre is separated by two perpendicular nodal planes (possible solutions of fault planes) creating four equal quadrants. These quadrants are related to the initial outward (dilatational) and inward (compressional) vertical ground motion on the seismograms. Generally, compressional quadrants are shaded and dilatational quadrants are left unshaded producing a P-wave first motion pattern similar to a beach ball. Strain at the source can be represented by the P-axis (bisector of dilatational quadrants) and the T-axis (bisector of compressional quadrants), which indicate the directions of maximum and minimum principal stresses, respectively.

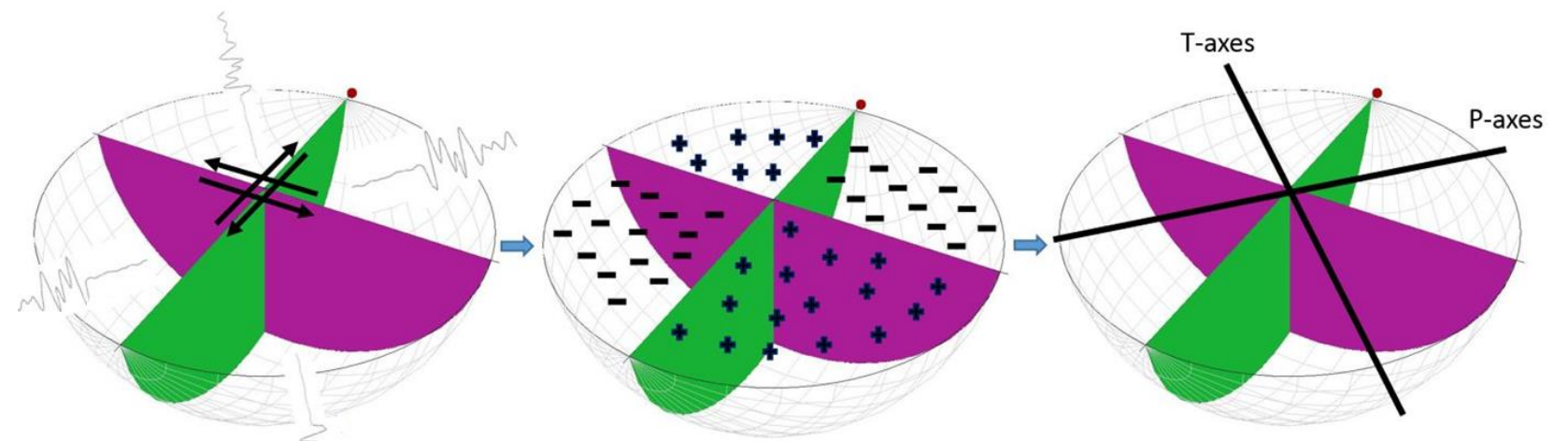

Figure 1 Characteristic of a double couple event and radiated waveforms (left), polarities and focal plane solutions (middle), and P-T axes (right)

Stress inversion has the potential to determine this more restricted information about the stress tensor at locations wherever there is sufficient seismic activity to apply the method. Although seismic stress inversion can potentially overcome the limited spatial coverage associated with conventional stress measurements, the method has not been widely used for mining applications, e.g. Urbancic et al. (1993, 1994), Snelling et al. (2013). 


\section{Description of Nickel Rim South Mine}

Nickel Rim South (NRS) is a modern mine using blast-hole open stoping with backfill as a means of bulk mining. It has been under operation since May 2009 and is located $22 \mathrm{~km}$ northeast of Sudbury, Ontario, Canada. Nickel and copper with significant precious metals credits are the main products of NRS. The orebody is located between 1,160 and 1,710 m below ground surface, strikes east-west and is steeply dipping. It consists of a nickel sulphide envelope in the hanging wall and a copper sulphide envelope in the footwall. The main portion of the nickel is located at the top of the orebody with a transition zone from nickel to copper in the middle, and the majority of the copper is hosted at the bottom the orebody. Stopes are accessed from three main levels: $1280 \mathrm{~m}$ level for nickel, $1480 \mathrm{~m}$ level for nickel and copper, and $1660 \mathrm{~m}$ level for nickel zone. There are two shaft accesses with three mining levels (Figure 2). Generally, the quality of the rock is good and the GSI is greater than 65 (Jalbout \& Simser 2014).

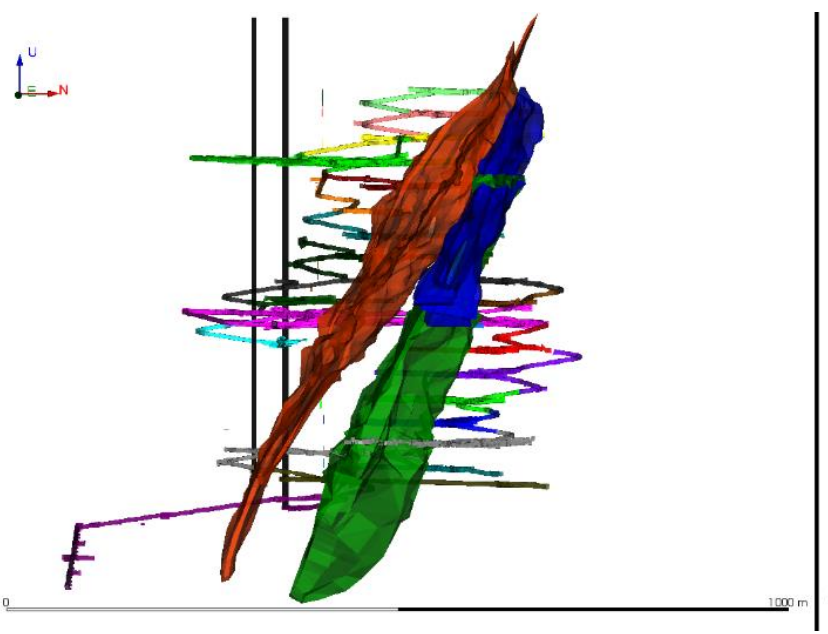

(a)

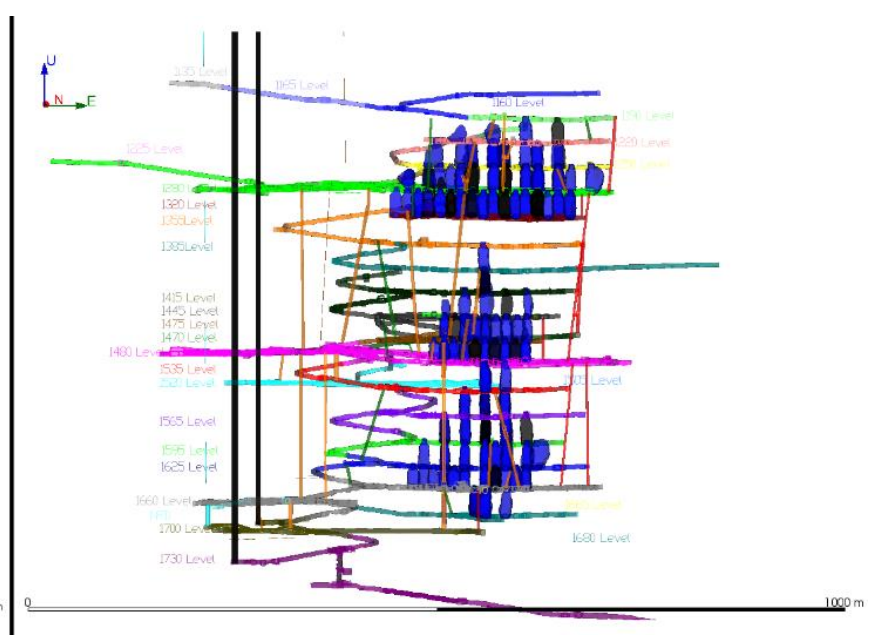

(b)

Figure 2 (a) Nickel (HW) and Copper (FW) orebodies, looking west. (b) Open stope sublevel stoping layout, looking north (image courtesy of ESG Solutions and NRS)

NRS orebody is structurally complex. Although there is no ductile shear in the mine, there are three major brittle fault systems: north-south striking and steeply dipping faults, low angle faults and, northeast and southwest striking steeply dipping faults. In conjunction with high in situ and mining induced stresses, rock fracture and seismicity is a characteristic response of the rock mass. Jalbout and Simser (2014) noted that the position, orientation, and slip along these faults caused events with high S-wave to P-wave energy ratio $\left(E_{s} / E_{p}\right)$ and as inferred by asymmetric clustering of seismic events across faults, changed the stress orientation locally by stress channelling. Event locations are determined using constant wave velocity model with $P$ and S-wave velocities of $6,160 \mathrm{~m} / \mathrm{s}$ and $3,590 \mathrm{~m} / \mathrm{s}$, respectively.

\subsection{History of stress measurement at NRS}

Overcoring stress measurements were carried out at the early stages of mining in 2006 and 2008 on 1480 Level (Turichshev \& Brummer 2008). Comparison of the measurements showed that, except for the slightly off-vertical orientation of the minor principal stress, the intermediate and major principal stresses did not appear to have consistent orientations. For instance, $\sigma_{1}$ was found to be more oriented northwest-southeast in the 2006 campaign, while it was E-W in the 2008 campaign (Figures 3(a) and 3(b)). Borehole survey information in 2016 on 1730 Level indicated a different orientation of $\sigma_{1}$. As shown in Figure 3, the Rose diagram for the orientation of the borehole breakouts on 1730 Level, implies a northeast-southwest direction of $\sigma_{1}$. It is important to note that the 2008 stress measurements were at a deeper level compared to those of 2006. In both cases, the measurement locations were sufficiently far from mining that they did not include any component of mining induced stress. The east-west orientation of the maximum principal stress was used for most of the stress models at the mine. 

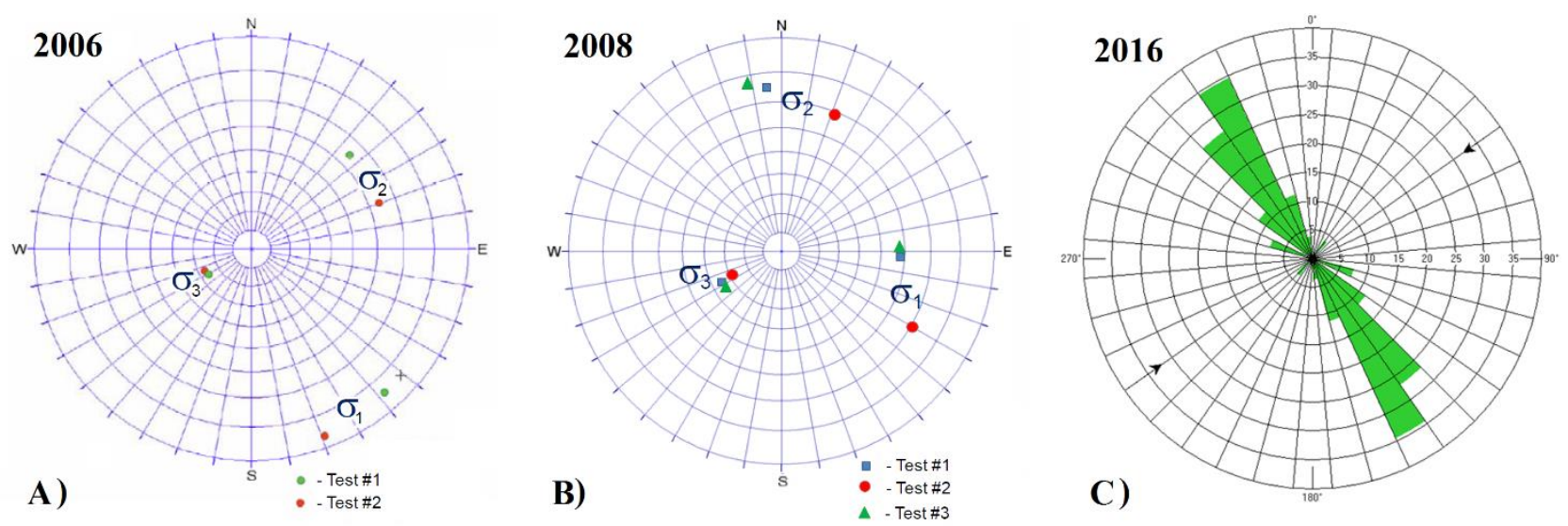

Figure 3 Orientation of major principal stresses obtained based on overcoring data from the test on 1480 level in: (a) 2006; and, (b) 2008 (Turichshev \& Brummer 2008). (c) Rose diagram for orientations of the borehole breakouts in 2016 (image courtesy of NRS)

\subsection{Seismicity at NRS}

The microseismic monitoring system has good coverage surrounding the active volume of mining. The system consists of 47 sensors with an average spacing of $120 \mathrm{~m}$ in the mine. Among these, 14 are $15 \mathrm{~Hz}$ triaxial geophones, two are $4.5 \mathrm{~Hz}$ triaxial geophones, and 31 are uniaxial accelerometers. This combination of sensors records events with moment magnitude above -3 . For this range, the uniaxial accelerometers record the events with moment magnitude between -3 and -0.5 , the $15 \mathrm{~Hz}$ triaxial geophones record events with moment magnitude between -2 and 1.5 , and the $4.5 \mathrm{~Hz}$ triaxial geophones record events with moment magnitude above 0.5 . The location accuracy varies between 5 and $20 \mathrm{~m}$ for events with high and low focal coverage (Jalbout \& Simser 2014), respectively. The recording of seismic data started in January 2009 (Figure 4).

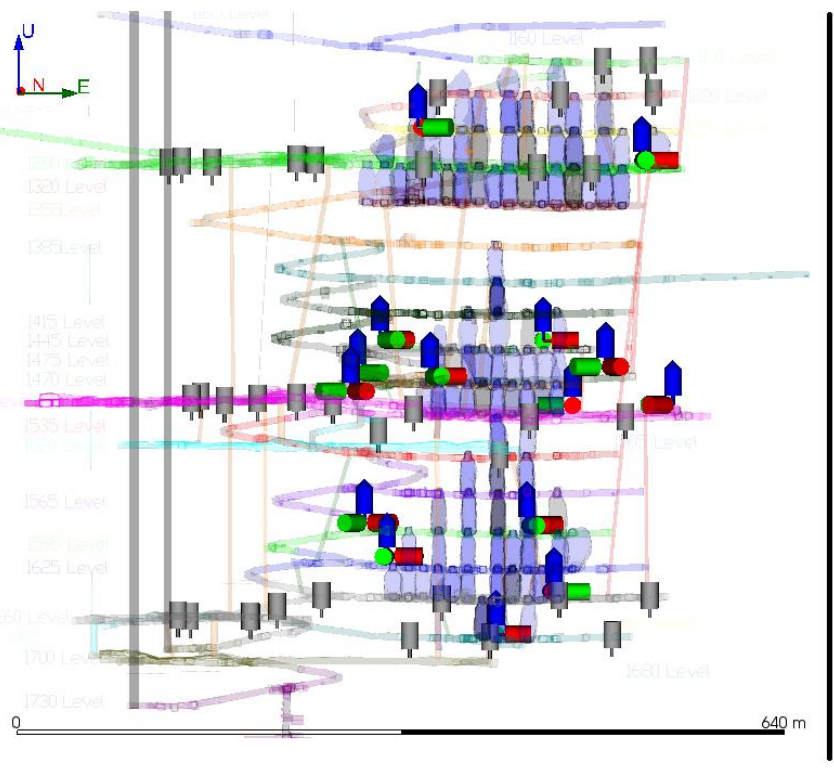

(a)

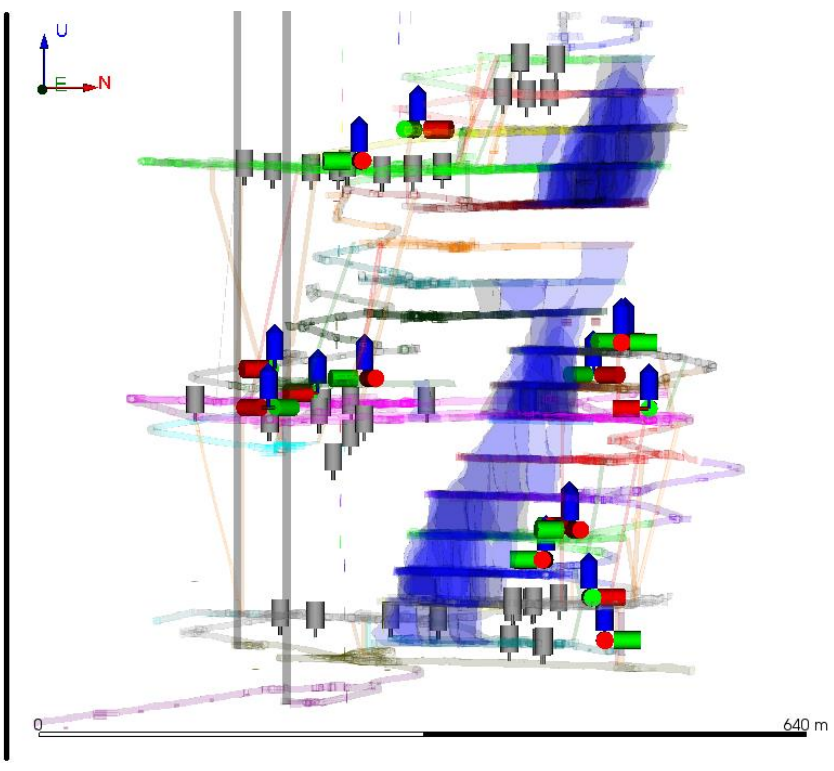

(b)

Figure 4 Sensors distribution around mining layout, uniaxial (grey) and triaxial (blue, red and green): (a) looking south; and, (b) looking west (image courtesy of ESG solutions and NRS) 
The seismic database used for the study contains all triggers (blasts, seismic events, and noise) from January 2009 to August 2014, with an average rate of approximately 11,000 events per month. All the seismic data are processed automatically (such as $\mathrm{P}$ and S-wave picking and filtering). For reducing noise effects and improving reliability of arrival time picking, events selected for the inversion procedure are processed manually. Blast waveforms are identified using the corresponding blast time at the mine and triggers with high P-wave amplitudes. Noise is also removed by identifying seismic records without patterns of $\mathrm{P}$ and S-wave phases, high amplitude, and their source location in the mine.

\section{Methodology}

The stress inversion process involves the analysis of several events within close proximity. As noted, one of the fundamental assumptions of the method is that the stress field within the volume containing the slip events is uniform. In seismically active mines there is generally a sufficient number of seismic events, but problems arise due to the presence of spatial stress gradients around mining excavations and near faults, which is where the seismic activity normally occurs.

For the application of seismic stress inversion, the seismically active volume of the mine is divided into a grid of volumetric elements. Seismic events contained within these volumes is used to generate the fault plane solutions for the stress inversion. Two competing criteria apply when considering this spatial discretisation:

- It is favourable to have many events in the volume to improve the tensor fit, but large volumes are less likely to satisfy the assumption of uniform stress due to stress gradients near excavations and faults.

- Small volumes that satisfy the uniform stress condition may not have enough events for a reliable stress tensor solution.

The sensitivity of the stress inversions to the spatial and temporal density of events will be discussed later.

\section{$3.1 \quad$ MOTSI}

Motion Stress Inversion (MOTSI) is a code developed by Abers and Gephart (2001) and is an extension of the Fault Mechanism Stress Inversion (FMSI) code (Gephart 1990a, 1990b). FMSI is the technique that without prior information of the fault plane solves for the best-fitting four-parameter stress tensor by inverting focal mechanism data. In contrast to FMSI, MOTSI is a nonlinear method that uses first motion data (not focal mechanisms) for seismic stress inversion. MOTSI estimates the stress tensor components with more complete uncertainties compared to other nonlinear methods. Also, it is able to adopt different focal mechanisms consistent with the first motions, as required by certain stress models. The confidence limits are somewhat larger than those produced by FMSI but are generally reasonable (Abers \& Gephart 2001). MOTSI provides a test for heterogeneity within a population, expressed as the statistic $d S$, which indicates rejection of the homogeneous stress hypothesis when it exceeds 2.32 (95\% confidence level) and negative values indicate improvement in the fit. Also another parameter, $d M$, indicates the similarity between the constrained and unconstrained focal mechanisms ( $d M=1$ represents no change). So, by implementing MOTSI it is possible to constrain the volume of events with uniform stress with a high confidence. This program needs two parameters that describe the probability of the first motion pick being correct (Abers \& Gephart 2001). The first, $\alpha$, is the radiation pattern amplitude below which pick reliability decreases significantly near nodal planes $(0<\alpha<1)$. The second, $\gamma$, is a probability of a first motion pick being wrong regardless of focal mechanism $(0<\gamma<1)$. For an abnormally noisy data set (characteristic of a mining environment) these values needed to be set to 0.1 and 0.2 , respectively (Abers \& Gephart 2001). These values do have an effect on the confidence intervals, but they have insignificant effect on the best fitting principal stresses.

There will still be spatial gradients near excavations. Estimating these gradients could be done using numerical stress analysis, but the goal of this paper is to explore an alternative that does not rely on prior knowledge of the stress field or development of a 3D numerical stress analysis model. With this intention, 
MOTSI software is used in order to estimate the location of the stress variations in the event clusters. MOTSI results help to guide the selection of the volume element size in terms of dividing space into volumes of approximately constant stress, i.e. smaller volumes in locations of higher stress gradients. The objective of the spatial discretisation study is to examine the error introduced by increasing the volume size in order to increase the event count. This will result in a loss of resolution of the spatial gradients and increase the error of inversion results due to a relaxation of the constant stress assumption in the inversion volume. If the degree of seismic activity at a mine is high, the event count in short time windows may be sufficient for spatial discretisation to produce reliable stress inversions. However, if the rate of seismicity is low, events may need to be accumulated over a longer time period. In this case, it is possible that stresses within fixed spatial volumes may change due to progressive mining induced stress changes, violating the constant stress requirement of the inversion process.

The temporal discretisation study follows a similar methodology, but a fixed volume relatively close to active mining is selected for the source data. MOTSI is again used to estimate the stress changes that are likely to be experienced by the study volume over the timeframe selected. This assists in quantifying the magnitude of the stress changes over time. Ideally, this will involve a volume that initially has moderate seismic activity but minimal stress gradients, followed by stress changes due to progressive mining. Once this has been established, the effects of mixing data from the same volume over different time periods, is examined. The objective is to determine the sensitivity of the inversion process to the relaxation of the constant stress assumption caused by changes in the stress field magnitude and orientation at similar points within fixed volumes.

\subsection{Filtering input data}

All data used for inversions are manually processed. In our case it is difficult to differentiate the S-wave polarities from the P-wave, and as a result, $\mathrm{S}$-waves are ignored and only the P-wave first-motion polarities are used. The orientations of the triaxial sensors are determined using the blast data (straight ray path travel of the P-wave between source and sensor). Sensors with very low amplitude signals and hardware problems are removed and not used for analysis. Triaxial sensors are rotated to the source, and to ensure that events are recorded by an adequate number of triaxial geophones (at least three), only events with moment magnitude greater than -1.4 are used (this cut-off is site specific) for stress inversion. To ensure that robust results are obtained, it is necessary to use events with polarities from at least seven sensors (uniaxial and triaxial), preferably evenly distributed around the source. Events with high $E_{s} / E_{p}$ were also selected (>10, although this value is site dependent) as the inversion process is based on the use of shear slip events.

\section{$4 \quad$ Results}

The three specific criteria used for selecting the clusters, were:

- In the early stages of mining.

- Far enough from major geological structures (to avoid the stress perturbation due to mining or slip along faults).

- In the appropriate coverage volume of the seismic system array (mixture of uniaxial and triaxial sensors and having at least seven first motion polarities).

Applying these criteria, the first suitable cluster was located in the middle level $(1,445 \mathrm{~m})$, far from active mining area and included 11 events (Figure 5). The $d S$ value of this cluster is 0.377 , which indicates that the state of stress within the selected volume is homogeneous, and only one event (event number 9) showed a major difference in the focal mechanism $(d M<0.7)$. To have a more homogeneous volume and better estimate of the stress tensor, this event was removed from the inversion cluster. A stress model computed from all calculated focal mechanisms has $\sigma_{1}$ plunging $3^{\circ}$ and trending $37^{\circ}$ and $\sigma_{3}$ trending $131^{\circ}$. These results, shown in the upper right of Figure 5 , are very close to the inferred northeast-southwest direction of $\sigma_{1}$ from the Rose diagram of the borehole breakouts on 1730 Level. 

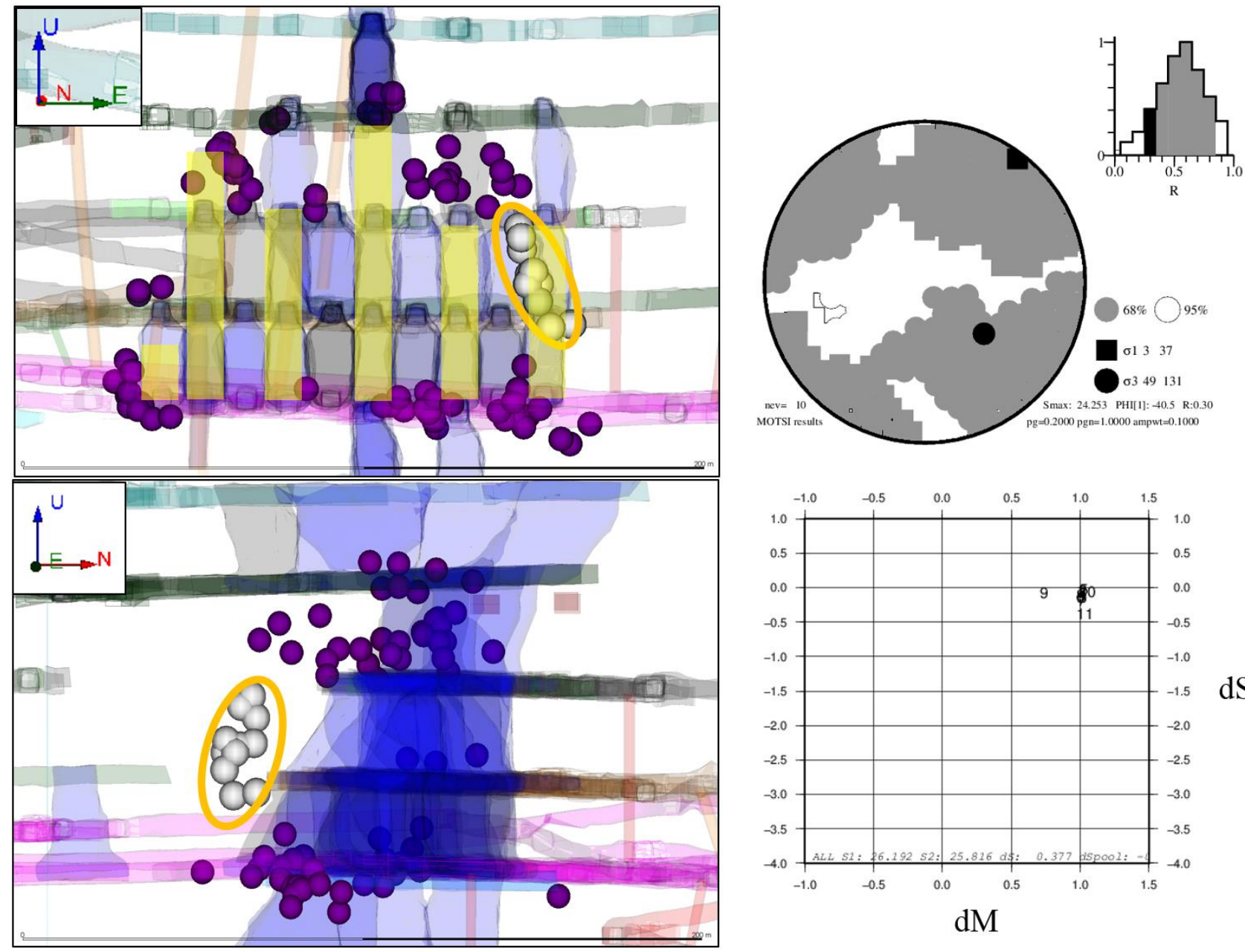

Figure 5 Location of the seismic events (purple circles), selected cluster (white circles inside the orange ellipsoid), final layout of the sublevel stoping (blue rectangles), the extracted stopes (yellow rectangles): (top left) looking north; (bottom left) looking west; (top right) $\mathrm{R}$ value and its marginal probability density function, with $68 \%$ and $95 \%$ confidence region represented by shaded and open bars, respectively. And the orientation of the $\sigma_{1}$ and $\sigma_{3}$, solid shows best model, shaded and open regions show $68 \%$ and $95 \%$ confidence limits, respectively ; and, (bottom right) $d S$ versus $d M$

For a period of seven months (from February to September 2011) in the middle level, more than 500 events in several clusters were manually processed and analysed using MOTSI. The inversion results around the middle level, shown in Figure 6, imply a variety of stress orientations including north-south, east-west and northeast-southwest (except for the cluster indicated by a red star), but the aggregate evidence implies an overall northeast-southwest orientation. 


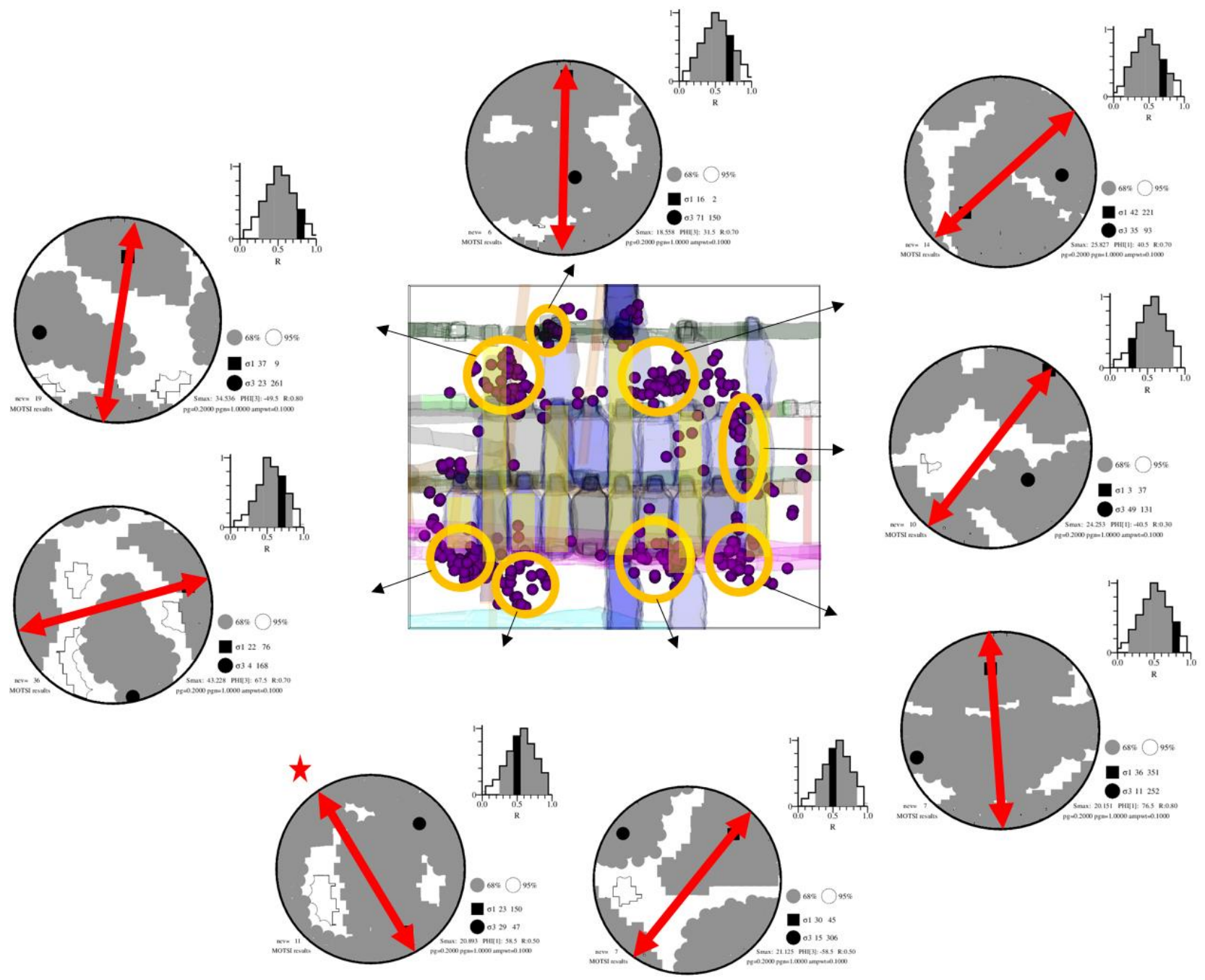

Figure 6 Location of the seismic events (purple circles), selected clusters (orange ellipsoids), final layout of the sublevel caving (blue rectangles), the extracted stopes (yellow rectangles), MOTSI inversion results (red arrows show $\sigma_{1}$ orientation)

\section{Discussion}

Unfortunately, reliable local overcoring measurements are not available for NRS. It is, therefore, not possible to directly compare the stress field information from seismic stress inversion with data from conventional stress measurements. However, the method appears to provide reasonable results when compared to the stress field orientation inferred from borehole breakout results. The variation in measured orientations of $\sigma_{1}$ and $\sigma_{2}$ (see Figure 3 ) is likely related to the close magnitude values of $\sigma_{1}$ and $\sigma_{2}$. In this scenario, by replacing the $\sigma_{1}$ with $\sigma_{2}$ orientations, the measured stresses would be more consistent with the orientations of borehole breakout results on 1730 Level and would be a closer match to the seismic stress inversion results.

Nonetheless, the stress inversion results indicate that the stress field is not uniform near large faults. New borehole breakout observations at the mine also show a similar pattern of principal stress orientations to those found from seismic stress inversion.

Large confidence limits of the $\sigma_{1}$ and $\sigma_{3}$ are due to the inherent characteristics (noisy, low moment magnitude, high frequency, etc.) of the mining induced seismic waveforms. Mining waveforms are not as clean as earthquake waveforms. Using more events in the inversion process could help to narrow the confidence limits, however, the homogeneity of the volume would be a concern. 


\section{$6 \quad$ Concluding remarks}

Preliminary mapping of the stress field in the early stages of mining has been carried out by implementing the seismic stress inversion method. Numerous seismic event clusters were used for the seismic stress inversion. Clusters recorded during the early stages of mining were selected in order to reduce mining induced perturbation of the stress field, which assisted in the refinement and development of procedures for applying a seismic stress inversion method in a mining environment.

Due to the noisy acoustic environment of the mine, and the inability of automated event recording codes to detect the true first arrival polarities, manual picking of events and the application of various filters significantly improved the identification and rejection of chaotic data, which could change the focal mechanism solutions and consequently the final stress tensor.

Increasing the volume size and relaxing the constant stress assumption may change the inversion results as larger volumes showed high values of $d S$ (indicator of inhomogeneity). Similar results were found by increasing the length of the time window.

The resulting double couple clusters in the middle level of the mine indicated a northeast-southwest orientation of $\sigma_{1}$. The orientation of $\sigma_{3}$ had trend east-west with plunge varying from vertical to horizontal. The effects of any localised mining induced stresses have not been removed from these results and, therefore, they do not, reflect the pre-mining state of stress required for the specification of numerical stress analysis boundary conditions.

These results are consistent with recent (2016) observations of borehole breakout in the 1730 Level of the mine.

\section{Acknowledgement}

We would like to thank the Natural Sciences and Research Council Collaborative Research and Development Project (NSERC CRD) and Glencore for financially supporting this research. We sincerely thank Glencore for making available the rock mechanics data, seismic data and technical documents associated with Nickel Rim South Mine. In particular, we would like to acknowledge the support of Mr Brad Simser. ESG Solutions is acknowledged for the use and support of their seismic analysis software, especially Dr Dave Collins and Dr Zara Hosseini. Last but not the least, we would like to thank Mr Hessam Mirsadeghi and Mr Hossein Khansari for their help in our software set-up.

\section{References}

Abers, GA \& Gephart, JW 2001, 'Direct inversion of earthquake first motions for both the stress tensor and focal mechanisms and application to southern California', Journal of Geophysical Research, vol. 106, no. 26, pp. 523-526.

Angelier, J 1990, 'Inversion of field data in fault tectonics to obtain the regional stress-III. A new rapid direction inversion method by analytical means', Geophysical Journal, vol. 103, pp. 363-376.

Angelier, J 1994, 'Fault slip analysis and palaeostress reconstruction', in PL Hancock (ed.), Continental Deformation, Pergamon Press, Oxford, pp. 53-100.

Baird, A, McKinnon, SD \& Godin, L 2009, 'Stress channelling and partitioning of seismicity in the Charlevoix seismic zone', Geophysical Journal International, vol. 179, pp. 559-568.

Baird, A, McKinnon, SD \& Godin, L 2010, 'Relationship between structures, stress and seismicity in the Charlevoix seismic zone revealed by 3-D geomechanical models: Implications for the seismotectonics of continental interiors', Journal of Geophysical Research, vol. 115.

Bott, MHP 1959, 'The mechanics of oblique slip faulting', Geological Magazine, vol. 96, pp. 109-117.

Delvaux, D \& Sperner, B 2003, 'Stress tensor inversion from fault kinematic indicators and focal mechanism data: the TENSOR program', in D Nieuwland (ed.), New Insights into Structural Interpretation and Modelling, Geological Society, London, pp. 75-100.

Etchecopar, A, Vasseur, G \& Daignieres, M 1981, 'An inverse problem in microtectonics for the determination of stress tensors from fault striation analysis', Journal of Structural Geology, vol. 3, pp. 51-65.

Gephart, JW 1990a, 'FMSI: a FORTRAN program for inverting fault/slickenslide and earthquake focal mechanism data to obtain the regional stress tensor, Comp', Computer and Geosciences, vol. 16, pp. 953-989.

Gephart, JW 1990b, 'Stress and the direction of slip on fault planes', Tectonics, vol. 9, no. 4, pp. 845-858. 
Gudmundsson, A \& Homberg, C 1999, 'Evolution of stress fields and faulting in seismic zones', Pure and Applied Geophysics, vol. 154, pp. 257-280.

Jalbout, A \& Simser, B 2014, 'Rock mechanics tools for mining in high stress ground conditions at Nickel Rim South Mine', in M Hudyma \& Y Potvin (eds), Proceedings of the Seventh International Seminar on Deep and High Stress Mining, Australian Centre for Geomechanics, Perth, Western Australia, pp. 189-208.

Ljunggren, C, Chang, Yanting, Janson, T \& Christiansson, R 2003, 'An overview of rock stress measurement methods', International Journal of Rock Mechanics \& Mining Sciences, vol. 40, pp. 975-989.

McKinnon, SD \& Garrido, I 1998, 'Fracture initiation, growth, and effect on stress field: a numerical investigation', Journal of Structural Geology, vol. 20, no. 12, pp. 1673-1689.

McKinnon, SD 2006, 'Triggering of seismicity remote from mining excavations', Rock Mechanics and Rock Engineering, vol. 39, no. 3, pp. 255-279.

McKinnon, SD \& Labrie, D 2006, 'Interpretation of stresses adjacent to the Cadillac Fault assuming marginal large-scale rock mass stability', in M Lu, CC Li, H Kjorholt \& H Dahle (eds), Proceedings of the International Symposium on In-situ Rock Stresses, Taylor \& Francis, Balkema, pp. 409-417.

Michael, AJ 1984, 'Determination of stress from slip data: Faults and folds', Journal of Geophysical Research, vol. 89, pp. 11517-11526.

Michael, AJ 1987, 'Stress rotation during the Coalinga aftershock sequence', Journal of Geophysical Research, vol. 92, no. B8, pp. 7963-7979.

Snelling, PE, Godin, L \& McKinnon, SD 2013, 'The role of geological structure and stress in triggering remote seismicity in Creighton Mine, Sudbury, Canada', International Journal of Rock Mechanics and Mining Sciences, vol. 58, pp. 166-179.

Turichshev, A \& Brummer, Rk 2008, In-Situ Rock Stress Measurements at the 1480 Level of the Nickel Rim South Project, Itasca Consulting Canada Inc., Xstrata Nickel, Nickel Rim South Project.

Urbancic, TI, Trifu, C-I \& Young, RP 1993, 'Microseismicity derived fault-planes and their relationship to focal mechanism, stress inversion, and geologic data', Geophysical Research Letters, vol. 20, no. 22, pp. 2475-2478.

Urbancic, TI, Trifu, C-I, Sampson-Forsyth, A \& Bawden, WF 1994, 'Potential for using focal mechanism and stress inversion studies to characterize active faulting in mines', Proceedings of the Fourth South American Congress on Rock Mechanics, Santiago, May 1994.

Wallace, RE 1951, 'Geometry of shearing stress and relation to faulting', The Journal of Geology, vol. 59, pp. 118-130.

Worotnicki \& Walton RJ 1976, 'Triaxial "hollow inclusion" gauges for the determination of rock stress in situ', Proceedings of the Symposium on Investigation of Stress in Rock: Advances in Stress Measurement, International Society for Rock Mechanics, Lisboa, pp. 1-8, supplement. 